\title{
DESAIN SISTEM PROSES PEMURNIAN BIOGAS BERBASIS PALM OIL MILL EFFLUENT (POME)
}

\section{DESIGN SYSTEM OF BIOGAS PALM OIL MILL EFFLUENT (POME) PURIFICATION PROCESS}

\author{
Ali Nurdin, Era R. Finalis, Arfiana, Fausiah, Endro W. Tjahjono \\ Pusat Teknologi Sumberdaya Energi dan Industri Kimia, BPPT \\ Laboratorium Teknologi Proses Industri Kimia, Gedung 225, Kawasan Puspiptek \\ E-mail: ali_nur@bppt.go.id
}

\begin{abstract}
Abstrak
Pabrik kelapa sawit menghasilkan 0,7-1 $\mathrm{m}^{3}$ limbah cair kelapa sawit atau palm oil mill effluent (POME) setiap ton TBS, dan kapasitas olah tandan buah segar (TBS) sebanyak 30 ton/jam diperkirakan menghasilkan POME sekitar $21 \mathrm{~m}^{3} / \mathrm{jam}\left(400 \mathrm{~m}^{3} / \mathrm{hari}\right)$ atau setara dengan $1,1 \mathrm{MWe}$. Proses penguraian POME akan menghasilkan biogas dengan kandungan utama metana $\left(\mathrm{CH}_{4}\right)$ berkisar $50-75 \%$, 25-45\% karbon dioksida $\left(\mathrm{CO}_{2}\right)$, dan sedikit kandungan gas lainnya seperti $\mathrm{H}_{2} \mathrm{~S}, \mathrm{H}_{2}, \mathrm{~N}_{2}$, dan uap air. Untuk memanfaatkan biogas hasil metanisasi dari POME agar dapat dikonversi menjadi listrik, maka terlebih dahulu harus dilakukan permurnian biogas untuk mengurangi kandungan $\mathrm{H}_{2} \mathrm{~S}$ dan uap air agar sesuai dengan spesifikasi umpan gas engine. Pada penelitian ini dilakukan pengembangan sistem proses pemurnian biogas dengan menggunakan bioscrubber untuk mengurangi kandungan gas $\mathrm{H}_{2} \mathrm{~S}$ dan dehumidifier untuk mengurangi kandungan uap air dalam produk biogas sehingga dihasilkan biogas dengan spesifikasi yang sesuai dengan umpan gas engine Bioscrubber yang digunakan adalah tipe Cross Flow Packed Bed Horizontal Scrubber dengan kapasitas $560 \mathrm{~kg} / \mathrm{jam}$, scrubbing agent berupa treated POME dengan jenis packing tipe Random Packing Pall Ring; sedangkan Dehumidifier yang digunakan adalah tipe Heat Exchanger Shell and Tube 1-1 pass.
\end{abstract}

Kata kunci: Biogas, pemurnian, POME, listrik

\begin{abstract}
Palm oil mills produce approximately $0.7-1 \mathrm{~m}^{3}$ of palm oil mill effluent (POME) per ton of FFB, while the capacity of fresh fruit bunches (FFB) of 30 tons / hour is estimated to produce POME of around $21 \mathrm{~m}^{3} /$ hour (400 $\mathrm{m}^{3}$ / day) or equivalent to $1.1 \mathrm{MWe}$. The POME decomposition process will produce biogas with the main content of methane $\left(\mathrm{CH}_{4}\right)$ in the range of 50$75 \%, 25-45 \%$ carbon dioxide $\left(\mathrm{CO}_{2}\right)$, and a few other gases such as $\mathrm{H}_{2} \mathrm{~S}$, $\mathrm{H}_{2}, \mathrm{~N}_{2}$, and water vapor. To utilize methaneized biogas from POME so that it can be converted into electricity, biogas purification must be done to reduce $\mathrm{H}_{2} \mathrm{~S}$ and water vapor content to meet the gas engine feed specifications. In this research, a biogas purification process system was developed by using Bioscrubber to reduce $\mathrm{H}_{2} \mathrm{~S}$ content and Dehumidifier to reduce the moisture content in biogas products so that biogas was produced with specifications in accordance with the gas feed engine. Bioscrubber used is a Cross Flow Packed Bed Horizontal Scrubber with capacity of $560 \mathrm{~kg} / \mathrm{hour}$; treated POME as a scrubbing agent, and using random packing pall ring as the packing type; while the Dehumidifier used is a Shell and Tube Heat Exchanger 1-1 Pass.
\end{abstract}

Keywords : biogas, purification, POME, electricity

Diterima (received ) : 11 Januari 2019, Direvisi (revised ) : 01 Maret 2019 ,

Disetujui (accepted) : 06 Maret 2019 


\section{PENDAHULUAN}

Indonesia merupakan negara penghasil minyak kelapa sawit terbesar di dunia dengan luas perkebunan sawit 11,26 juta hektar, dan produksi crude palm oil (CPO) sebesar 31,07 juta ton pada tahun 2015 menurut data Ditjen Perkebunan Kementerian Pertanian ${ }^{1)}$. Produksi minyak ini tentunya diikuti dengan tingginya produksi limbah yang merupakan hasil/produk sampingan yang masih mempunyai nilai ekonomi dan energi yang tinggi apabila dimanfaatkan seperti cangkang, batang sawit, tandan kosong, serat (fiber), pelepah dan limbah cair kelapa sawit "palm oil mills efluent'(POME) dan tersebar di lokasi-lokasi sentra tanaman sawit dan pengolahan buah sawit.

Pabrik kelapa sawit menghasilkan 0,7-1 $\mathrm{m}^{3}$ limbah cair kelapa sawit setiap ton tandan buah segar (TBS). Pabrik kelapa sawit (PKS) dengan kapasitas olah tandan buah segar (TBS) sebanyak 30 ton/jam diperkirakan menghasilkan POME sekitar $21 \mathrm{~m}^{3} / \mathrm{jam}(400$ $\mathrm{m}^{3} /$ hari) yang setara dengan $1,1 \mathrm{MWe}^{2)}$. Karakteristik POME yang dihasilkan dari PKS memiliki suhu $60-80^{\circ} \mathrm{C}, \mathrm{pH} 3,3-4,6$, kental, berwarna kecoklatan dengan kandungan padatan, minyak dan lemak 190-14.720 $\mathrm{mg} / \mathrm{l}$, COD 15.103-65.100 mg/l, dan BOD 8.200-35.000 mg//2). Agar dapat dibuang ke lingkungan, POME perlu melalui tahapan treatment terlebih dahulu untuk mengurangi kandungan tersebut sesuai dengan pedoman pengelolaan limbah indsutri sawit.

Penguraian POME secara anaerob dianggap merupakan metode penanganan POME yang menguntungkan karena selain dapat mengatasi masalah limbah tetapi juga mampu menghasilkan sumber energi. Oleh sebab itu metode ini merupakan metode yang paling banyak digunakan ${ }^{3)}$. Limbah POME harus diolah karena dapat berakibat buruk terhadap lingkungan karena memiliki kandungan gas rumah kaca yang cukup tinggi, yang berkontribusi terhadap pemanasan global $^{4}$.

Proses penguraian POMEakan menghasilkan biogas dengan kandungan utama metana $\left(\mathrm{CH}_{4}\right)$ berkisar antara50\% sampai $75 \%$. Gas ini muncul sebagai akibat dari proses perombakan senyawa - senyawa organik secara anaerobik. Biogas merupakan campuran gas yang diproduksi oleh sekelompok mikroorganisme dengan menguraikan material biodegradable pada kondisi anaerobik. Biogas sebagian besar terdiri atas $50-75 \%$ metana $\left(\mathrm{CH}_{4}\right), 25-45 \%$ karbon dioksida $\left(\mathrm{CO}_{2}\right)$, dan sedikit kandungan gas lainnya seperti $\mathrm{H}_{2} \mathrm{~S}, \mathrm{H}_{2}, \mathrm{~N}_{2}$, dan uap air2). Unit konversi biogas diperlukan untuk memanfaatkan gas metana tersebut sebagai sumber energi untuk pembangkit listrik dengan berbahan baku limbah cair sawit (POME).Dengan meningkatnya kebutuhan akan bahan bakar dan energi serta berkurangnya jumlah bahan bakar fosil, maka dibutuhkan suatu alternatif. Biogas merupakan salah satu alternatif untuk memenuhi kebutuhan tersebut karena biogas selain dapat digunakan untuk bahan bakar kendaraandapat pula digunakan untuk menghasilkan panas dan listrik $^{5}$. Sebelum dimanfaatkan untuk menghasilkan listrik, biogas dari digester perlu melalui proses pemurnian terlebih dahuluuntuk mengurangi kandungan senyawa $\mathrm{H}_{2} \mathrm{Ssehingga}$ biogas dapat memenuhi spesifikasi umpan gas engine.

Bioscrubber dapat digunakan untuk mengurangi kandungan $\mathrm{H}_{2} \mathrm{~S}$ dalam biogas dengan efisiensi pemisahan mencapai $\left.98 \%{ }^{6}\right)$.Sedangkan dari riset yang telah dilakukan oleh Tosati dan Jinsiriwanit (2013), Bioscrubber mampu mengurangi kandungan $\mathrm{H}_{2} \mathrm{~S}$ dalam umpan biogas hingga $80 \%{ }^{7}$.

Kelebihan utama penggunaan bioscrubberdalam proses pemurnian biogas adalah mampu menangani konsentrasi $\mathrm{H}_{2} \mathrm{~S}$ yang cukup tinggi dan berfluktuasi ${ }^{8}$. Efisiensi pemisahan umumnya diperngaruhi oleh beberapa parameter dan dapat meningkat seiring dengan kenaikan tinggi packing, jenis packing, jenis mikroorganisme, laju alir gas umpan, dan liquid ${ }^{\beta}$.

Kegiatan penelitian ini bertujuan untuk melakukan desain sistem proses pemurnian biogas yang diproduksi dari limbah cair pabrik kelapa sawit (POME). Pada desain proses ini digunakan bioscrubber untuk mengurangi kandungan $\mathrm{H}_{2} \mathrm{~S}$ dan alat dehumidifier untuk memisahkan air yang terkandung dalam biogas.

\section{TINJAUAN PUSTAKA}

Biogas merupakan gas yang dihasilkan dari proses penguraian bahan-bahanorganik oleh mikroorganisme pada kondisi anaerob $^{10)}$. Untuk dapat menghasilkan biogas, limbah cair dari pabrik kelapa sawit (POME) yang dihasilkan dari proses milling kelapa sawit dapat diproses secara anerob baik melalui proses yang konvensional menggunakan kolam atau secara lebihmodern dengan menggunakan tangki digester terbuka ${ }^{11)}$, ataupun menggunakan digester tipecontinous stirred tank 
reactor(CSTR). Adapun prinsip pembuatan biogas adalah adanya dekomposisi bahan organik secara anaerob untuk menghasilkan gas yang sebagian besar terdiri atas gas metana $\left(\mathrm{CH}_{4}\right)$, selain itu juga terkandung gas karbondioksida $\left(\mathrm{CO}_{2}\right)$, sejumlah kecil air dan gas hidrogen disulfida $\left(\mathrm{H}_{2} \mathrm{~S}\right)^{12}$. Biogas lebih ringan daripada udara dan memiliki temperatur nyala pada rentang $650^{\circ} \mathrm{C}$ sampai $750^{\circ} \mathrm{C}$.Biogas sedikit berbau karena mengandung hidrogen sulfat $\left(\mathrm{H}_{2} \mathrm{~S}\right)$. Proses produksi biogas terdiri atas beberapa tahap yaitu:

\section{Tahap Penguraian Anaerobik}

Penguraian anaerobik berlangsung dalam beberapa tahap dan beberapa kelompok mikroorganisme yang berbeda untuk menguraikan zat organik ${ }^{13)}$ dengan menggunakan ketersediaan energi yang terbatas. Adapun tahapan yang terjadi yaitu hidrolisis (reaksi dengan air), acidification atau fermentation ${ }^{14)}$, pembentukan asam asetat, dan pembentukan gas metana yang terjadi dua (2) rute yaitu rute primer dan sekunder.Pada rute primer, fermentasi produk utama yang berasal dari tahap pembentukan asam yakni asam asetat diubah menjadi metana dan karbon dioksida.Reaksi keseluruhan adalah sebagai berikut.

$$
\mathrm{CH}_{3} \mathrm{COOH} \rightarrow \mathrm{CH}_{4}+\mathrm{CO}_{2}
$$

Rute sekunder menggunakan hidrogen untuk mengurangi $\mathrm{CO}_{2}$ untuk menghasilkan $\mathrm{CH}_{4}$ dengan metanogen hidrogenofilik.

$$
4 \mathrm{H}_{2}+\mathrm{CO}_{2} \rightarrow \mathrm{CH}_{4}+2 \mathrm{H}_{2} \mathrm{O}
$$

\section{Pretreatment POME}

Bahan baku biogas dari pabrik kelapa sawit berupa POME yang merupakan limbah cair pada suhu sekitar $70^{\circ} \mathrm{C}$ dengan komposisi COD, BOD, dan acidity tertentu yang umum dari proses pengolahan kelapa sawit. POME merupakan cairan berwarna kecoklatan dan viskos, yang memiliki kandungan air 95-96\%, padatan sekitar 4\% hingga $5 \%$ termasuk suspended solid $2-4 \%$ dan $0,6-0,7 \%$ minyak, dan grease. Selain itu, POME juga mengandung asam amino dan nutrient inorganik ( $\mathrm{Na}, \mathrm{K}, \mathrm{Ca}, \mathrm{Mg}, \mathrm{Mn}, \mathrm{Fe}$, $\mathrm{Zn}, \mathrm{Cu}, \mathrm{Co}$, dan $\mathrm{Cd})^{15}$. Secara garis besar pre-treatment dapat dilakukan secara fisik maupun kimiawi tergantung pada spesifikasi POME keluar dari pabrik kelapa sawit.
Limbah cair pabrik kelapa sawit (POME) mengandung protein, karbohidrat, dan glukosa yang memiliki senyawa karbon yang dapat diolah dengan bantuan bakteri untuk dapat menghasilkan biogas dengan kandungan utama gas metana dan gas karbon dioksida. Tahap awal adalah proses hidrolisis polimer dari limbah cair dengan menggunakan enzim lipase dan enzim protease yang digunakan untuk memecah masing-masing ikatan lemak dan protein. Hasil akhir dari proses ini adalah limbah dalam senyawa terlarut. Kemudian dengan bantuan bakteri metana, larutan tersebut siap untuk diolah menghasilkan gas metana dengan produk ikutan berupa gas karbon dioksida.

\section{Sistem Pembersihan Biogas}

Untuk dapat memanfaatkan biogas hasil metanisasi dari POME harus terlebih dahulu dilakukan perlakuan untuk menyesuaikan spesifikasi biogas sebagai bahan bakar gas dengan persyaratan mesin gas yang digunakan. Komponen-komponen di dalam biogas yang perlu dihilangkan ataupun dikurangi meliputi kandungan air, padatan, dan senyawa sulfur. Pengurangan masingmasing komponen ini besarannya ditentukan oleh jenis mesin konversi yang digunakan.Sistem pemurnian gas biogas perlu dipertimbangkan secara cermat sesuai dengan penggunaannya.

\section{METODOLOGI PENELITIAN}

Kegiatan awal penelitian mencakup survei dan kajian literatur untuk menentukan metode dan teknologi pemurnian yang digunakan, selanjutnya dilakukan penentuan desain basis sistem pemurnian biogas dengan batasan biogas digunakan untuk menggerakkan gas engine, sistem produksi biogas dari POME menggunakan digester model Continous Stirred Tank Reactor (CSTR), dan sistem pemurnian dilakukan terhadap gas hasil proses metanasi di digester. Alur proses pemurnian biogas kemudian dituangkan dalam bentuk process flow diagram (PFD) yang kemudian digunakan untuk dasar perhitungan pada heat and mass balance (HMB). Dari HMB kemudian dapat dilakukan perhitungan desain dan spesifikasi alat yang digunakan dalam proses pemurnian biogas. Skema tahapan desain sistem proses pemurnian biogas tertera pada Gambar 1 berikut.

\section{Produksi Biogas}




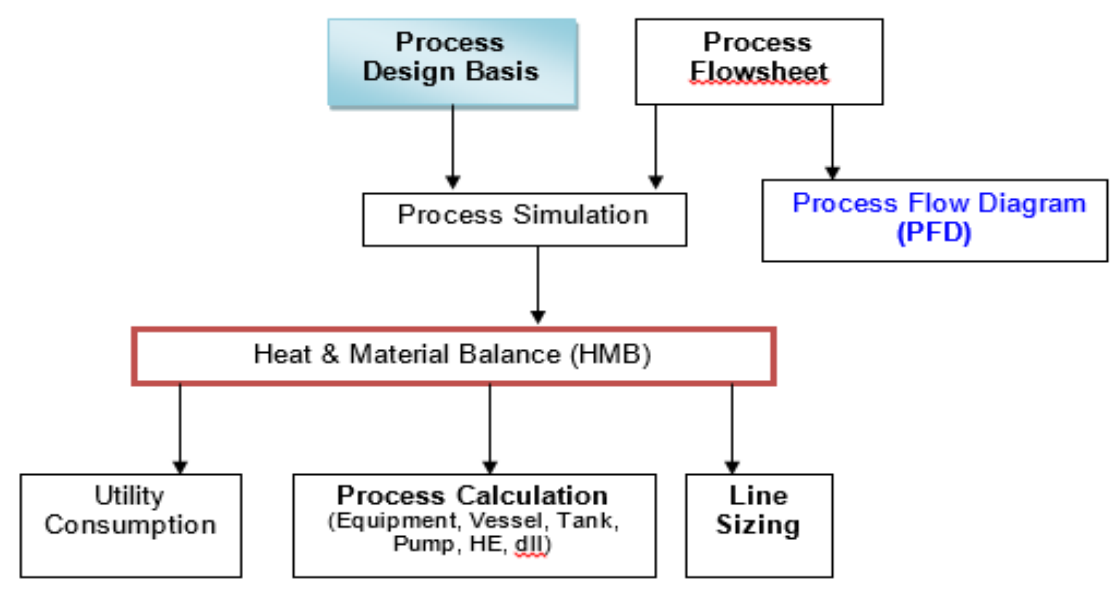

Gambar 1.

Skema tahapan desain sistem pemurnian biogas

Pada jurnal ini, pembahasan desain sistem proses pemurnian biogas difokuskan kepada desain alat Bioscrubber yang digunakan untuk memisahkan kandungan gas hidrogen disulfida $\left(\mathrm{H}_{2} \mathrm{~S}\right)$ dan Dehumidifier yang berfungsi untuk mengurangi kandungan air dalam biogas.

\section{HASIL DAN PEMBAHASAN}

Bioscrubber yang digunakan adalah tipe cross flow packed bed horizontal scrubber dengan scrubbing agent berupa treated POME. Gambaran desain bioscrubber yang digunakan dapat dilihat pada Gambar 2 berikut.

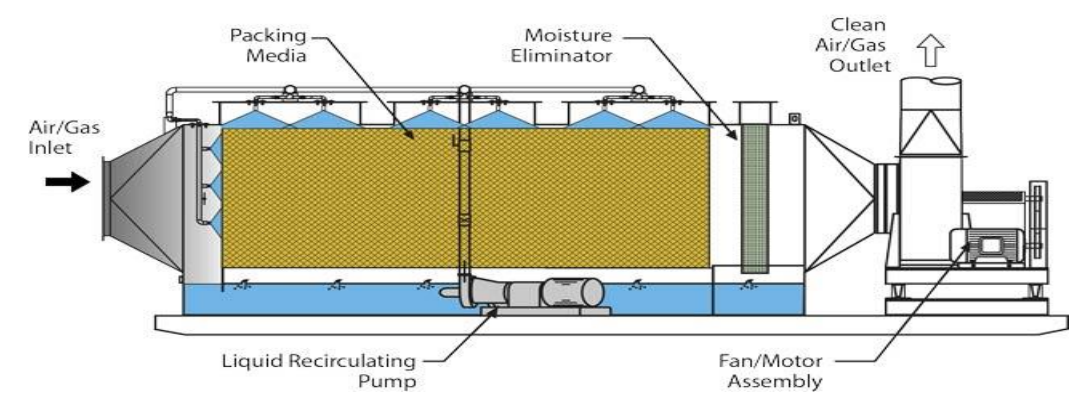

Gambar 2.

Cross flow packed bed horizontal scrubber ${ }^{16}$

Tabel1.

Komposisi Umpan Bioscrubber

\begin{tabular}{ccc}
\hline Komponen & $\mathbf{k g} / \mathbf{j}$ & $\mathbf{y}_{\mathbf{i}}$ \\
\hline $\mathrm{H}_{2}(\mathrm{~g})$ & 0,23 & 0,001 \\
$\mathrm{CO}(\mathrm{g})$ & 2,01 & 0,01 \\
$\mathrm{CO}_{2}(\mathrm{~g})$ & 151,90 & 0,53 \\
$\mathrm{CH}_{4}(\mathrm{~g})$ & 120,72 & 0,42 \\
$\mathrm{~N}_{2}(\mathrm{~g})$ & 3,56 & 0,01 \\
$\mathrm{H}_{2} \mathrm{O}(\mathrm{g})$ & 7,87 & 0,03 \\
$\mathrm{H}_{2} \mathrm{~S}(\mathrm{~g})$ & 0,63 & 0,002 \\
Jumlah & 286,92 & 1,00 \\
\hline
\end{tabular}

Adapun kelebihan dari penggunaan cross flow packed bed scrubber adalah jumlah scrubbing agent/liquid bisa lebih besar, dapat mengakomodasi kecepatan gas yang lebih dan mengurangi kemungkinan terjadi sumbatan atau plugging.Komposisi umpan Bioscrubber dapat dilihat pada Tabel 1.

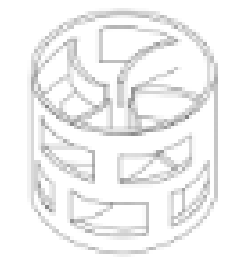

Gambar 3.

Jenis packing yang digunakan ${ }^{16)}$

Pada perhitungan desain Bioscrubber, digunakan jumlah scrubbing agent yang berlebih untuk memaksimalkan penyerapan gas $\mathrm{H}_{2} \mathrm{~S}$, jenis packing yang digunakan adalah randompackingpall ring dengan 
ukuran packing yang digunakan harus sesuai dengan diameter scrubber, dan rasio L/D adalah 4. Bentuk packing yang digunakan ditunjukkan pada Gambar 3.

Persamaan-persamaan yang digunakan pada perhitungan Bioscrubber yaitu:

$V_{d}=k[(\rho L-\rho G) / \rho G]^{1 / 2}$

$\mathrm{NOG}=\ln \mathrm{y}_{1} / \mathrm{y}_{2}$

$\mathrm{t}_{\mathrm{s}}$ minimum $=\frac{p x r_{\mathbb{R}}}{(f x E)-(0.6 x p)}$

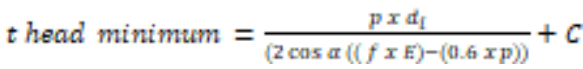

Persamaan (1), (2), (3) $)^{17)}$, dan $(4)^{17)}$ digunakan untuk perhitungan desain Bioscubber yaitu untuk menentukan kecepatan gas dalam scrubber, menghitung number of transfer unit, ketebalan shell dan head.

Dari hasil perhitungan diperoleh kapasitas Bioscrubber sebesar 560 kg/jam, laju volumetric 350,76 $\mathrm{m}^{3} / \mathrm{jam}$, kecepatan gas dalam Bioscrubber sebesar $0,07 \mathrm{~m} / \mathrm{s}$, cross sectional area (A) 1,34 $\mathrm{m}^{2}$, diameter Bioscrubber 1,31 m, panjang shell 5,22 m, number of transfer unit 2,46, height of transfer unit 0,6 $\mathrm{m}$, panjang tumpukan/bed packing dalam Bioscrubber 1,47 m, panjang inlet 0,65 m, dan panjang outlet 0,65 m. Pada bagian bawah Bioscrubber dilengkapi dengan tangki penampung yang berfungsi untuk menampung liquid. Tangki penampung memiliki tutup atas dan bawah berbentuk datar dengan panjang penampung sama dengan panjang shell. Dari perhitungan diperoleh dimensi penampung, panjang 5,22 $\mathrm{m}$, lebar $1,31 \mathrm{~m}$, dan tinggi $0,64 \mathrm{~m}$.

Bravo et al. (2018) melakukan penelitian tentang simulasi proses produksi biogas dengan menggunakan Anaerobic Bioscrubber. Hasil yang diperoleh mampu memberikan efisiensi pemisahan hingga 93\% dengan Bioscrubber yang memiliki diameter $0,5 \mathrm{~m}$ dan ketinggian material packing $2 \mathrm{~m}^{18}$ ). Sedangkan dari penelitian yang dilakukan oleh Potivichayanon et al. (2006), penggunaan Bioscrubberskala kecil dengan diameter 0,03 $\mathrm{m}$ dan tinggi $0,5 \mathrm{~m}$ dapat memisahkan kandungan gas hidrogen disulfida hingga $98 \%{ }^{6}$. Dengan demikian penggunaan Bioscrubber cukup teruji dan dapat memberikan hasil yang baik untuk proses pemisahan hidrogen disulfida.

Dehumidifier digunakan untuk mengurangi kandungan air dalam biogas dengan metode mendinginkan umpan biogas sehingga air yang terkandung akan mengembun dan terpisah dari aliran biogas. Tipe Dehumidifier yang digunakan adalah Heat ExchangerShell and Tube 1-1 pass dengan aliran gas pada bagian tube dan cooling water pada bagian shell. Temperatur biogas in adalah pada $35^{\circ} \mathrm{C}$, dan temperatur keluar pada $12^{\circ} \mathrm{C}$, sedangkan cooling water pada suhu in sebesar $6^{\circ} \mathrm{C}$ dan suhu keluar pada $10^{\circ} \mathrm{C}$. skema aliran ditunjukkan pada Gambar 4.

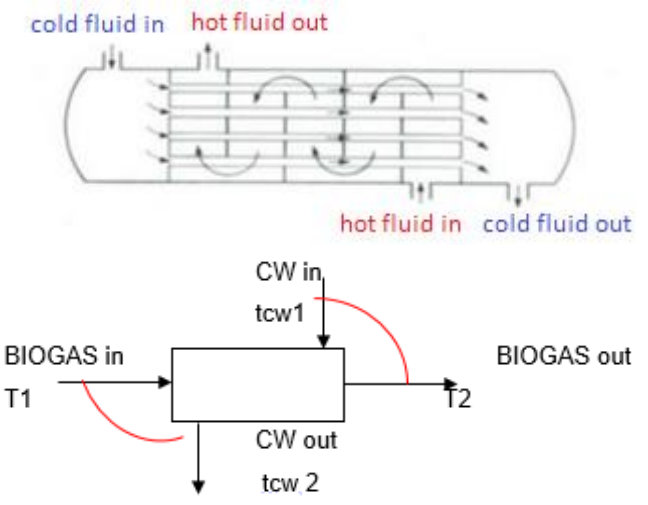

Gambar 4

Skema aliran pada Dehumidifier

Komposisi umpan masuk Dehumidifier dapat dilihat pada Tabel 2.

Tabel 2.

Komposisi Umpan Dehumidifier

\begin{tabular}{ccc}
\hline Komponen & $\mathbf{k g} / \mathbf{j}$ & $\mathbf{~ k m o l} / \mathbf{j}$ \\
\hline $\mathrm{H}_{2}(\mathrm{~g})$ & 0,22 & 0,11 \\
$\mathrm{CO}(\mathrm{g})$ & 1,93 & 0,07 \\
$\mathrm{CO}_{2}(\mathrm{~g})$ & 145,82 & 3,31 \\
$\mathrm{CH}_{4}(\mathrm{~g})$ & 115,89 & 7,24 \\
$\mathrm{~N}_{2}(\mathrm{~g})$ & 3,42 & 0,12 \\
$\mathrm{H}_{2} \mathrm{O}(\mathrm{g})$ & 15,74 & 0,87 \\
$\mathrm{H}_{2} \mathrm{~S}(\mathrm{~g})$ & 0,12 & 0,004 \\
Jumlah & 283,14 & 11,74 \\
\hline
\end{tabular}

Dari perhitungan neraca panas pada Dehumidifier diketahui bahwa beban panas yang harus dihilangkan adalah sebesar 35.276.590,4 Joule/jam sehingga diperlukan cooling water sebanyak 2.099,79 $\mathrm{kg} / \mathrm{jam}$.Tahapan desain shell and tubedilakukan baik untuk bagian tube maupun shell yang mengacu pada Handbook Process Heat Transfer oleh D. Q. Kern.

Tahapan perhitungan desain Dehumidifieradalah menghitung $\Delta \mathrm{T}$ (LMTD), menghitung temperatur kritis pada tube dan shell (Tc dan tc), trial dan perhitungan Ud sesuai jumlah tube. Lalu dilanjutkan dengan perhitungan pada bagian shell dan tube 
yang mencakup perhitungan flow area, mass velocity, perhitungan Reynold Number, penentuan nilai $\mathrm{jH}$ (faktor transfer panas), ho dan hio (koefisien transfer panas), serta kecepatan aliran dalam tube. Pressure drop pada sisi shell dan tube juga dihitung untuk mengetahui apakah pressure drop tiap bagian masih memenuhi persyaratan desain (maksimum 10 psi masing - masing untuk sisi shell maupun tube). Desain Dehumidifier juga harus memenuhi dirt factor $(\mathrm{Rd})$ yang diizinkan yaitu maksimum 0,003 untuk natural gas dan sejenisnya ${ }^{19)}$. Hasil perhitungan desain menghasilkan Dehumidifier dengan luas perpindahan panas $34,88 \mathrm{ft}^{2}$, Uc (clean overall coefficient) adalah 39,06, $\mathrm{Rd}_{\text {required }} 0,002$, pressure drop shell 0,055 psi, pressure drop tube 3,88 psi, diameter shell 8 inch, ukuran baffle 2,5 inch, pressure drop shell 0,055 psi, ukuran tube 0,75 inch, pitch 1 inch, dan jumlah tube 37.

\section{SIMPULAN}

Bioscrubber yang digunakan untuk menyerap kandungan gas $\mathrm{H}_{2} \mathrm{~S}$ adalah tipe cross flow packed bed horizontal scrubber dengan kapasitas $560 \mathrm{~kg} / \mathrm{jam}$ dan scrubbing agent berupa treated POME dengan jenis packing yang digunakan adalah random packing pall ring. Berdasarkan hasil perhitungan diperoleh dimensi Bioscrubber dengan diameter scrubber 1,31 $\mathrm{m}$, panjang shell 5,22 m, panjang tumpukan/bed packing dalam scrubber 1,47 m, number of transfer unit 2,46, height of transfer unit 0,6 m, panjang inlet 0,65 $\mathrm{m}$, panjang outlet 0,65 m dan dimensi tangki penampung dengan panjang $5,22 \mathrm{~m}$, lebar $1,31 \mathrm{~m}$, dan tinggi 0,64 $\mathrm{m}$. Sedangkan,Dehumidifier yang digunakan untuk mengurangi kandungan air dalam biogas adalah tipe Heat Exchanger Shell and Tube 1-1 pass dengan aliran gas pada bagian tube dan cooling water pada bagian shell. Hasil perhitungan desain menghasilkan Dehumidifier dengan luas perpindahan panas $34,88 \mathrm{ft}^{2}$, Uc (clean overall coefficient) adalah $39,06, \mathrm{Rd}_{\text {required }} 0,002$, pressure drop shell 0,055 psi, pressure drop tube 3,88 psi, diameter shell 8 inch, ukuran baffle 2,5 inch, pressure drop shell 0,055 psi, ukuran tube 0,75 inch, pitch 1 inch, dan jumlah tube 37 .

\section{UCAPAN TERIMA KASIH}

\footnotetext{
Riset ini terlaksana atas bantuan dana dari kegiatan Insentif Sistem Inovasi Nasional (SINas) 2018, Kementerian Riset, Teknologi, dan Pendidikan Tinggi.
}

\section{DAFTAR PUSTAKA}

1. Direktorat Jenderal Perkebunan.2016. Statistik Perkebunan Indonesia : Kelapa Sawit $2015-2017$.

2. Ade, S. R., et al. 2015. Handbook POME-to-Biogas : Project Development in Indonesia, $2^{\text {nd }}$ Edition. Winrock International.

3. Choong, Y. Y., Chou K. W., dan Norli, I. 2018. Strategies for Improving Biogas Production of Pal Oil Mill Effluent (POME) Anaerobic Digestion : A Critical Review. Renewable and Sustainable Energy Reviews, vol. 82 : 2993 - 3006.

4. Munirah, M. Z., dan Abdul, R. M. 2018. An Overview on Conversation Technologies to Produce Value Added Products from $\mathrm{CH}_{4}$ and $\mathrm{CO}_{2}$ as Major Biogas Constitutuents. Renewable and Sustainable Energy Reviews, vol. 98 : 56 $-63$.

5. Wandera, S. M., Qiao, W., Algapani, D. E., Bi, S., Yin., D. M., Qi, X. Y., Liu, Y., L., Dach, J., dan Dong, R. 2018. Searching for Possibilities to Improve the Performance of Full Scale Agricultural Biogas Plants. Renewable Energy, vol. $116: 720-727$.

6. Potivichayanon, S., Pokethitiyook, P., dan Kruatrachue, M. 2006. Hydrogen Sulfide Removal by a Novel Fixed - Film Bioscrubber System. Process Biochemistry, vol. $41: 708-715$.

7. Tosati, J., dan Jinsiriwanit, S. 2013. Improving the Quality of Hydrogen Sulfide Contaminated Biogas by Bioscrubber. Current Opinion in Biotechnology, vol. 24S : S48 - S143.

8. Nishimura, S., dan Yoda, M. Removal of Hydrogen Sulfide from an Anaerobic Biogas using a Bio-Scrubber. Water Sci. Technology, vol. $36: 349-356$.

9. Koe, L. C. C., dan Yang, F. A. 2000. A Bioscrubber for Hydrogen Sulphide Removal. Water Sci. Technology, vol 41 : $141-145$.

10. Awe, O. W., Zhao, Y., Nzihou. A., Minh, D. P., and Lyczko, N. 2017. A Review of Biogas Utilisation, Purification, and Upgrading Technologies. Waste Biomass Valor. DOI 10.1007/s12649-016-9826-4.

11. Poh, P. E., dan Chong, M. F. 2010. Biomethanation of Palm Oil Mill Effluent (POME) with a Thermophilic Culture Cultivated using POME as a Substrate. Chemical Engineering Journal, vol. 164 : $146-154$.

12. Bharathiraja, B., Sudharsanaa, T., Bharghavi, A., Jayamuthunagai, J. dan 
Praveenkumar, R. 2016. Biohydrogen dan Biogas - An Overview of Feedstocks and Enhancement Process. Fuel, vol. $185: 810-828$.

13. Patinvoh, R. J., Osadolor, O. A., Chandolias, K., Horvath, I. S., Taherzadeh, M. J. 2017. Innovative Pretreatment Strategies for Biogas Production. Biosource Technology, vol. $224: 13-24$.

14. Trisakti, B., Manalu, V., Taslim, I., dan Fauzi, M. 2015. Acidogenesis of Palm Oil Mill Effluent to Produce Biogas: Effect of Hydraulic Retention Time and $\mathrm{pH}$. Procedia - Social and Behavioral Sciences, vol. $195: 2466-2474$.

15. Ahmed, Y., Yaakob, Z., Akhtar, P., dan Sopian, K. 2015. Production of Biogas and Performance Evaluation of Exixting Treatment Processes in Palm Oil Mill Effluent (POME). Renewable and Sustainable Energy Reviews, vol. 42 : 1260 - 1278.
16. Packed Bed Wet Scrubbers : https://www.monroeenvironmental.com/ai r-pollution-control/packed-bed-wetscrubbers/

17. Brownell, L. E. and Young, E.H. 1959 Process Equipment Design $3^{\text {ed }}$. John Wiley\& Sons. New York.

18. Bravo, F. J., ALvares, H. J. M., Penya, R., San, V., Gabaldon, C. 2018. Aspen Plus Process - Simulation Model :Producing Biogas from VOC Emissions in an Anaerobic Bioscrubber. Journal of Environmental Management, vol. 213 : 530 - 540.Kern, D. Q. 1983. Process Heat Transfer. McGraw - Hill Book Company, New York. 
(halaman ini sengaja dikosongkan) 